\title{
Different Types of Plant-Based Fiber in a Protein-Containing Meal During Satiety and Hunger States: A Randomized Controlled Trial
}

\author{
Hilal Hızlı Güldemir ${ }^{1 *}$ Şahika Türken² ${ }^{2}$ sman Güldemir ${ }^{3}$ \\ 1. Faculty of Health Sciences, Department of Nutrition and Dietetics, Kutahya Health Sciences University, \\ Kutahya, Turkey \\ 2. Center of Clinical Obesity and Metabolic Surgery, Istanbul, Turkey \\ 3. Vocational School of Eskisehir, Cookery Department, Anadolu University, Eskisehir, Turkey \\ * E-mail of the corresponding author: hilal.hizliguldemir@ksbu.edu.tr
}

\begin{abstract}
Fiber content of a meal is distinctly effective in appetite. There are studies that draw attention to the effects of protein and fiber combined meals on short-term satiety and food intake. This study was performed to examine the effects of different fiber sources in a protein-containing meal during satiety and hunger. The study was carried out once a week on the same day and for three-week duration, with total of 17 randomly selected participants with ages between 18 and 24 years. The test foods containing different vegetable fiber sources (chickpeas and oats) were given to the participants every week as isocaloric, which have been the control food for a week. The satiety status was evaluated by visual analog scale (VAS) for total of five times as immediately before the test food consumption and at 30, 60,90 and 120 minutes after consumption. Fasting and postprandial blood glucose levels were measured. A 24-hour retrospective food consumption record was obtained the next day. There was no statistically significant difference among the VAS results of the three groups, which were given chickpea + yoghurt $(\mathrm{CY})$, oat + yoghurt $(\mathrm{OY})$, and yoghurt $(\mathrm{Y})$ as control $(\mathrm{p}>0.05)$. No significant difference was observed in ad libitum food intake after the test food and daily energy intake determined by 24-hour food consumption records $(p>0.05)$. However, the energy and macronutrient intake of the OY group at the ad libitum lunch and the rest of the day were significantly lower than that of CY. The difference between blood glucose levels during hunger and satiety states of CY group was found significant $(\mathrm{p}<0.05)$. Collectively, the VAS findings revealed that consumption of fiber-enriched meal has a significant effect on short-term satiety, daily energy intake and blood glucose level control compared to a protein-only meal, however no significant difference was observed between the types of fiber consumed. Registered under ClinicalTrials.gov Identifier no. NCT 04601025.
\end{abstract}

Keywords: hunger, fiber, protein, satiety, appetite

DOI: $10.7176 / \mathrm{JHMN} / 85-13$

Publication date: January $31^{\text {st }} 2021$

\section{Introduction}

Dietary fiber is the component that constitute the edible part of plants, which resists being digested and absorbed by human intestine (Du et al. 2010). It has been shown in studies that dietary fiber provides protection against multiple diseases, including diabetes, cardiovascular diseases, colon cancer and obesity. Fibers are effective in body weight control through various physiological mechanisms (Slavin 2013). As a whole grain, oat is extremely rich in dietary fiber called $\beta$-glucan. There are studies showing that oat reduces the human glycemic response compared to similar wheat products and provides glucose control (Rebello et al. 2016). Chickpeas and/or hummus support healthy eating patterns recommended by both Mediterranean-style diet and dietary guidelines. A recent study conducted with adult participants ( $\geq 19$ years) who were enrolled in National Health and Nutrition Examination Survey (NHANES) represented that those who consume chickpeas/hummus had higher intake of dietary fibers ( $24.4 \pm 0.7 \mathrm{vs} .10 .1 \pm 0.1 \mathrm{~g} /$ day) and many other nutrients (Wallace et al. 2016). Other studies have also shown that bean consumption (not specific to chickpeas) is associated with higher nutrient intake, particularly two important nutrients of public health concern (potassium and dietary fiber) and other nutrients such as plant protein, folate, zinc, iron, and magnesium, along with lower intake of saturated fat and total fat. Nutrition studies also support an increase in dietary fiber intake with the consumption of chickpeas (Pittaway et al. 2008, Murty et al. 2010). In addition, chickpeas are among the lowest glycemic index (GI) foods. An inverse relationship has been reported between the GI of the food and its satiation level. Therefore, the low GI properties of chickpeas suggest 
that they might be highly filling and beneficial in controlling nutrient intake (Johnson et al. 2005).

Nutrient content of a food is extremely significant in appetite control. Foods that differ in nutrient content represent various physiological effects. Some of these effects are signals that induce satiety. Foods, which increase satiety, such as fiber-rich nutrients have been hot research topic (Bellisle et al. 2012, Rebello et al. 2016). The proposed mechanisms of fibers altering satiety and body weight is the movement of high energy density foods, increased chewing movement resulting in greater saliva and gastric juice secretion, delayed gastric emptying, delayed food intake and digestion, and fermentation (Slavin 2005). In addition, consuming macronutrients all at once will have a synergistic effect, since each macronutrient provides satiety through independent mechanisms. Therefore, fiber is believed to limit acute food intake when consumed with protein (El Khoury et al. 2014). The ingestion of animal protein, compared to vegetal protein, has been shown to induce higher energy expenditure. However, these effects seem to be masked when a mixed meal is consumed. Additionally, fiber-rich foods contribute to reduced energy density of the whole diet (Martini et al. 2018).

Therefore, in this study, we aimed to investigate the effects of different fiber sources in a protein-containing meal on appetite, food intake and blood glucose levels in volunteers between 18 and 24 years.

\section{Materials and Methods}

This study was performed as a single-blinded within-subject repeated-measures randomized crossover design with total of 17 female university students who studies Nutrition and Dietetics, between the ages of 18-24 years. The study population was randomly selected using sampling method, from 28.05.2019 to 24.06.2019 by Istanbul Medipol University Anthropometry Laboratory. Participants were reached through general announcements made in classrooms. The sample size required was based on previous short-term food intake studies with a power of 0.80 and an alpha of $<0.05$ (Akhavan et al. 2010, Panahi et al. 2013). For this research, the permissions were obtained from Istanbul Medipol University Non-Invasive Clinical Research Ethics Committee (No: 10840098-604.01.01E.14959). This study was performed within the guidelines of the Helsinki Declaration. All participants were informed about the purpose of this research and were ensured that their information would remain confidential.

The enrollment criteria dictated that the participant should have age range of 18-24 years, study at the university, not smoke, not doing regular physical activity, not using medications, have normal BMI according to the World Health Organization (18.5-24.9 $\mathrm{kg} / \mathrm{m}^{2}$ ), satisfy blood donation criteria, along with not suffering from diabetes, abnormal thyroid problem, polycystic ovary syndrome, gastrointestinal disorder, food allergy or intolerance. Individuals who smoke, with her menstrual cycle days, follow a special diet program, have eating disorder, are vegan or vegetarian, do not consume legumes, have gluten or lactose intolerance, have a chronic disease eg. obesity, diabetes, cardiovascular health diseases, inflammatory bowel diseases, are pregnant or breastfeeding were excluded from the study. This study was registered under ClinicalTrials.gov Identifier no. NCT 04601025.

The protocol and procedures are similar to those reported in previous studies (Akhavan et al. 2010, Panahi et al. 2013). Participants were asked to arrive at the same time and on the same day of the week for all sessions. They were invited to the experiment place at 09.00 AM. Initially, they were detailly informed about the research. Each participant has signed informed consent and voluntary participation forms. Then, the data collection forms were distributed. Data collection forms included demographic information, health and nutritional habits, meal palatability questionnaire, as well as visual analog scales (VAS) that they fill out every half hour. Participants were asked to remain seated throughout the experimental session.

Participants were asked to discontinue their food intake at least eight hours before coming to the test place each week. The test foods were provided in random order once per week by researchers. The test group consumed chickpeas and yoghurt (CY), oats and yoghurt (OY) or only yoghurt (Y) randomly once a week for total of three weeks. Data obtained from the only yoghurt (Y) consumption was assessed as control. Each test food contained $135 \mathrm{kcal}$ of energy in total and was served with $200 \mathrm{ml}$ of water. Test foods with $70 \mathrm{~g}$ boiled chickpeas and $80 \mathrm{~g}$ full-fat yoghurt; $100 \mathrm{~g}$ of boiled oats and $80 \mathrm{~g}$ of full-fat yoghurt and $200 \mathrm{~g}$ of full-fat plain yoghurt were served as isocaloric meals. The test foods were blended for three minutes to ensure textural homogeneity and 0.5 grams of salt added for flavor similarity. Energy and nutrient composition data are shown in Table 1. 


Table 1. Energy and nutrient compositions of the test food
\begin{tabular}{|l|c|c|c|}
\hline Parameters & CY & OY & Y \\
\hline Weight (g) & 150 & 180 & 200 \\
\hline Energy (kcal) & 135.7 & 135.7 & 135.3 \\
\hline Carbohydrate (g) & 15.3 & 17.6 & 8.7 \\
\hline Fiber (g) & 6.9 & 2.3 & 0 \\
\hline Protein (g) & 9.4 & 6.2 & 7.8 \\
\hline Fat (g) & 4.1 & 4.5 & 7.7 \\
\hline
\end{tabular}

Blood glucose levels were measured using a glucometer (Accu-Chek, Roche Diagnostics, Turkey). Initially, the participants' finger needled, the first blood was wiped and then the second blood was collected. Fasting blood glucose levels (FBG) were measured at the beginning of the experiment (before the test food was given), whereas postprandial blood glucose levels (PBG) were recorded after two hours.

The approved Visual Analogue Scale (VAS) was used to evaluate both the hunger-satiety status of the participants and the taste and sensory components of the meals. In this scale, the distance of the mark placed on a $100 \mathrm{~mm}$ linear line from the starting point was recorded using a measure and the scores of the individuals related to appetite were determined. The palatability scale was used to evaluate the taste of the meals. According to this scale, the participants were asked to evaluate the meals given in terms of visuality, smell, taste, aftertaste and general pleasure on a scale of $100 \mathrm{~mm}$.

Two hours after the test, the participants were provided ad libitum sandwiches, which consist of pre-weighed white bread, full-fat cheese, tomato and lettuce, along with pre-weighed two types of instant fruit juices. The amount (one medium size) and volume $(180 \mathrm{ml})$ of one sandwich serving, along with the juice were pre-standardized. It was calculated that the sandwich and fruit juice contained average of $380 \mathrm{kcal}$ and $59 \mathrm{kcal}$, respectively. Participants were informed that they are allowed to consume sandwiches and fruit juices as much as they wanted, and the amounts consumed were recorded. Test meals and lunch meals, which were served ad libitum, were prepared using products obtained from a local grocery store.

Participants were called the next day and their 24-hour food consumption records were obtained. Daily energy and nutrients intakes were analyzed using Nutrition Information System (BeBiS 8.1), which is widely used and accepted in Turkey (Erhardt 2019).

The data obtained through the experimental study were transferred to a computer and analyzed using the SPSS 22.0 (SPSS Inc., Chicago, IL, USA) statistical software. The compatibility of the numerical values recorded during the experiment to the normal distribution was examined by the Shapiro-Wilk test and the repeated ANOVA test. VAS data on satiety indicators was analyzed using a repeated measures ANCOVA with baseline measurement as the covariate. Test meal and test meal $\times$ time interaction was considered. Data was given as mean \pm standard deviation unless otherwise stated. $\mathrm{p}<0.05$ was considered statistically significant. Data on the area under the curve (AUC) for VAS and graphics were obtained using GraphPad Prism version 8.0.2 (Graphpad Software Inc., La Jolla, CA, USA) and analyzed using ANOVA.

The study has several limitations. Due to the small number of participants, the study may be underpowered. We performed the measurements of glucose with a glucometer and not with blood from a vain, also only at the beginning and at the end. Therefore, it has not been possible to do a suitable glucose response curve. Also, the lack of insulin measurement in physiological parameters is a limitation.

\section{Results}

The characteristics of the individuals are shown in Table 2 . The participants, who were university students, were mean age $21.06 \pm 1.03$ years, and mean BMI was $20.82 \pm 2.03 \mathrm{~kg} / \mathrm{m}^{2}$. 
Table 2. General characteristics of individuals

\begin{tabular}{|l|l|}
\hline Parameters & Mean \pm SD \\
\hline Age (year) & $21.06 \pm 1.03$ \\
\hline Body Weight (kg) & $57.20 \pm 8.08$ \\
\hline BMI (kg/m $\left.{ }^{\mathbf{2}}\right)$ & $20.82 \pm 2.03$ \\
\hline
\end{tabular}

In Table 3, the VAS scores of the groups, the palatability scores of the meals, ad libitum lunch and 24-hour energy and nutrient intakes are represented. Although there were differences in the AUC values of VAS scores, the obtained findings were not statistically significant $(\mathrm{p}>0.05)$. There was no significant difference in visuality, smell; excluding taste, aftertaste and palatability parameters, however the scores of CY and OY groups were higher than that of Y group. Thus, it was concluded that the consumability of all test foods were similar.

Comparing the energy intake of ad libitum lunches, it was observed that the calorie intake of OY group was lower than the others, yet no statistically significant difference has been observed among groups $(\mathrm{p}=0.377)$. Mean daily energy intakes were highest in Y group $(2101.7 \pm 518.3 \mathrm{kcal})$ and lowest in OY group (1839.54 $\pm 456.09 \mathrm{kcal})$. While the Y group exhibited the greatest carbohydrate intake (254.6 $\pm 72.6 \mathrm{~g})$, OY group had the lowest $(215.4 \pm$ $53.2 \mathrm{~g})$. The variations in terms of protein and fat intakes were also similar and no statistically significant difference has been found $(\mathrm{p}>0.05)$.

Table 3. Parameters obtained in research

\begin{tabular}{|l|c|c|c|c|}
\hline Parameters & CY & OY & Y & p value \\
\hline How hungry?* & $4820 \pm 977.8$ & $5154 \pm 926$ & $5868 \pm 1110$ & $0.012^{\mathrm{a}}$ \\
\hline How full?* & $5599 \pm 911.5$ & $6130 \pm 942.2$ & $5074 \pm 1024$ & $0.009^{\mathrm{b}}$ \\
\hline $\begin{array}{l}\text { Amount of food that } \\
\text { could be consumed* }\end{array}$ & $5420 \pm 1012$ & $5381 \pm 966.2$ & $5857 \pm 1083$ & 0.329 \\
\hline $\begin{array}{l}\text { Prospective food } \\
\text { consumption* }\end{array}$ & $5179 \pm 949.6$ & $5480 \pm 1037$ & $5054 \pm 1070$ & 0.462 \\
\hline $\begin{array}{l}\text { Desire for savory } \\
\text { food consumption* }\end{array}$ & $3219 \pm 839.6$ & $4309 \pm 1118$ & $4024 \pm 1203$ & $0.013^{\mathrm{c}}$ \\
\hline $\begin{array}{l}\text { Ad libitum lunch } \\
\text { intake (kcal) }\end{array}$ & $416.00 \pm 153.95$ & $351.00 \pm 136.65$ & $416.00 \pm 172.64$ & 0.377 \\
\hline $\begin{array}{l}\text { Total daily energy } \\
\text { intake (kcal) }\end{array}$ & $2018.71 \pm 564.78$ & $1839.54 \pm 456.09$ & $2101.75 \pm 518.39$ & 0.295 \\
\hline Carbohydrate (g) & $251.04 \pm 84.22$ & $215.43 \pm 53.24$ & $254.64 \pm 72.63$ & 0.208 \\
\hline Protein (g) & $79.41 \pm 15.84$ & $74.28 \pm 23.14$ & $79.62 \pm 26.02$ & 0.693 \\
\hline Fat (g) & $74.35 \pm 28.27$ & $73.50 \pm 23.73$ & $82.63 \pm 22.93$ & 0.457 \\
\hline Fiber (g) & $23.55 \pm 8.81$ & $21.51 \pm 14.72$ & $23.61 \pm 8.78$ & 0.808 \\
\hline Visuality & $56.52 \pm 22.94$ & $51.64 \pm 29.76$ & $44.76 \pm 29.27$ & 0.614 \\
\hline Smell & $36.76 \pm 24.50$ & $41.00 \pm 28.86$ & $34.17 \pm 22.03$ & 0.773 \\
\hline Taste & $42.17 \pm 22.71$ & $54.52 \pm 27.26$ & $26.05 \pm 20.43$ & 0.009 \\
\hline Aftertaste & $42.11 \pm 21.10$ & $55.29 \pm 28.53$ & $27.82 \pm 17.37$ & 0.005 \\
\hline Palatability & $54.05 \pm 27.14$ & $54.11 \pm 29.02$ & $35.17 \pm 19.69$ & 0.037 \\
\hline Mean AUC & & & \\
\hline
\end{tabular}

* Mean AUC \pm SEM, repeated ANOVA test, ${ }^{\mathrm{a}}(\mathrm{CY}-\mathrm{Y}),{ }^{\mathrm{b}}(\mathrm{OY}-\mathrm{Y}),{ }^{\mathrm{c}}(\mathrm{CY}-\mathrm{OY})$.

The differences in blood glucose levels among the groups are demonstrated in Table 4. PBG levels were 99.588 $\mathrm{mg} / \mathrm{dL}, 95.764 \mathrm{mg} / \mathrm{dL}$ and $101.294 \mathrm{mg} / \mathrm{dL}$ in CY, OY and Y groups, respectively. Statistically significant decrease has been detected between fasting and postprandial blood glucose levels in the CY test group $(p=0.011)$, but there was no significant difference in OY and Y groups $(\mathrm{p}>0.05)$. 
Table 4. Changes in blood glucose levels

\begin{tabular}{|c|c|c|c|}
\hline Groups & $\begin{array}{c}\text { Fasting blood glucose } \\
\text { level (FBG) (mg/dL) }\end{array}$ & $\begin{array}{c}\text { Postprandial blood } \\
\text { glucose level (PBG) } \\
\text { (mg/dL) }\end{array}$ & p value \\
\hline CY & $88.52 \pm 10.04$ & $99.58 \pm 10.24$ & $\mathbf{0 . 0 0 3}$ \\
\hline OY & $86.11 \pm 10.72$ & $95.76 \pm 10.35$ & 0.062 \\
\hline Y & $91.29 \pm 11.66$ & $101.29 \pm 9.36$ & 0.075 \\
\hline
\end{tabular}

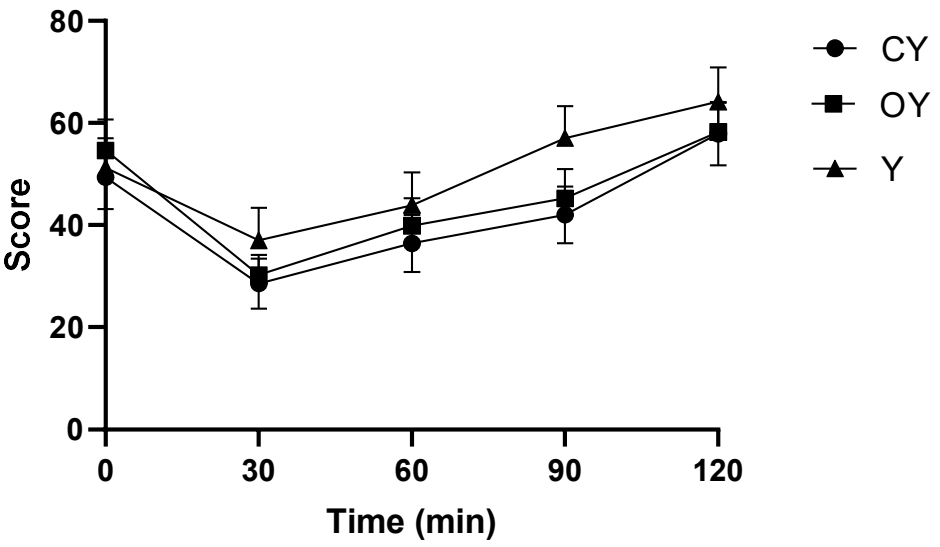

Figure 1. Hunger Scores

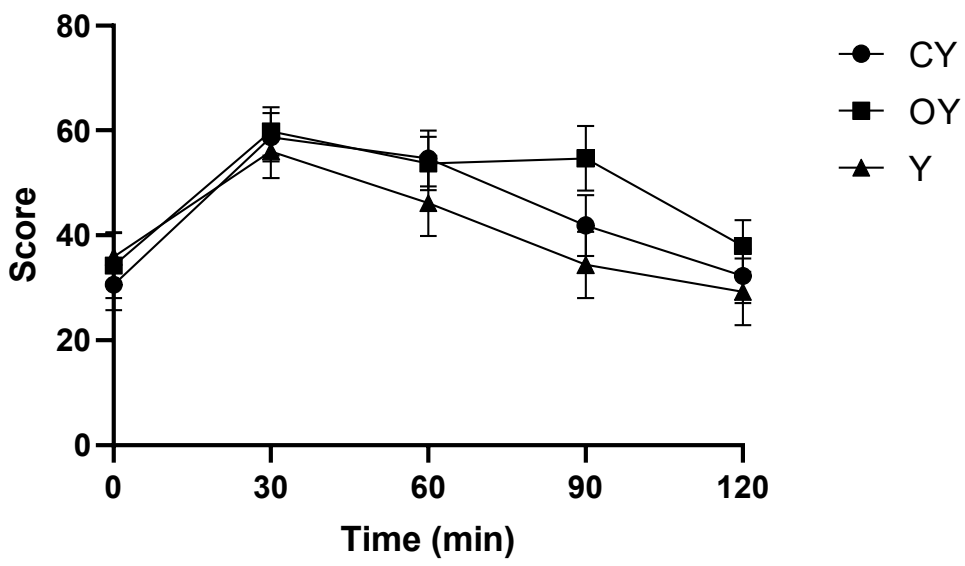

Figure 2. Satiety Scores 


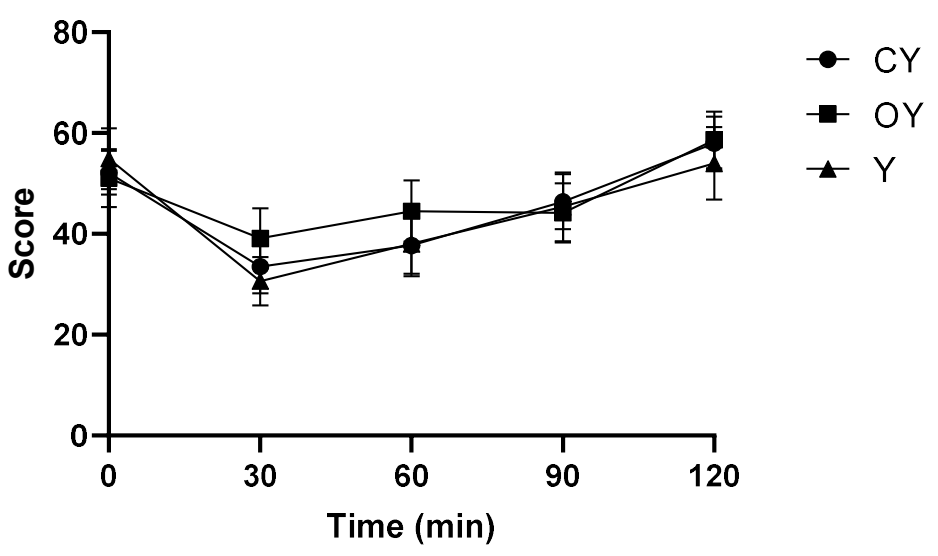

Figure 3. Prospective food consumption

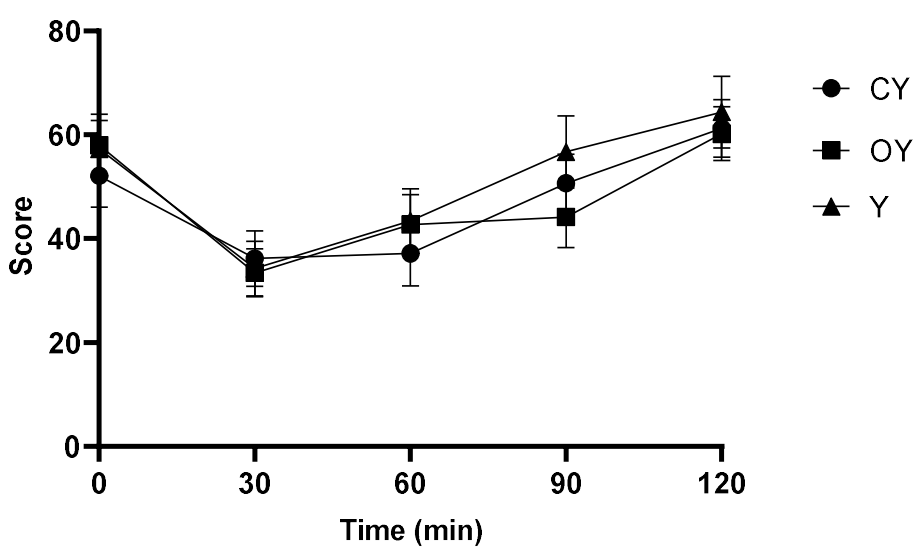

Figure 4. Amount of food that could be consumed

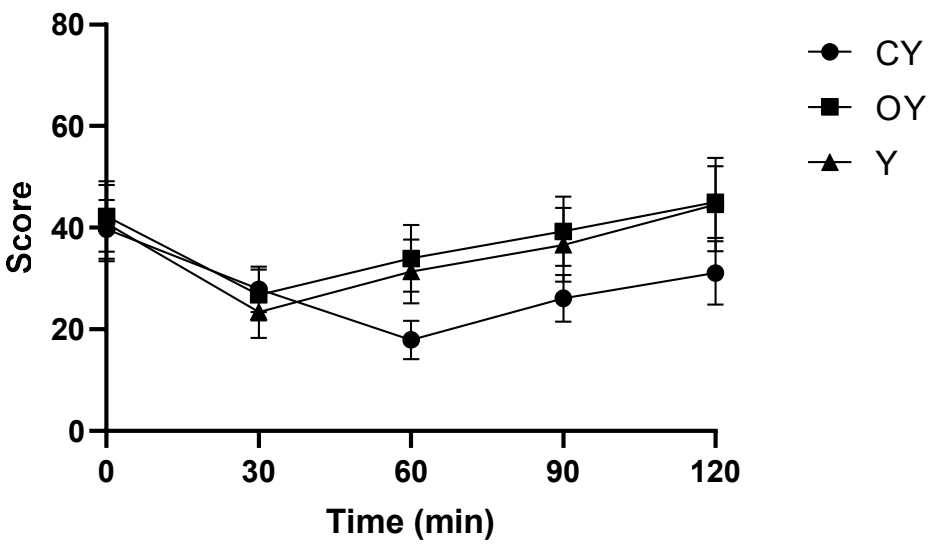

Figure 5. Desire for savory foods

The differences between the VAS scores of the groups recorded for 120 minutes are shown in Figure 1-5. As demonstrated in Figure 1, hunger scores increased after a decrease until the $30^{\text {th }}$ minute in all weeks, whereas the experimental groups were close to each other but lower than the control group at $120^{\text {th }}$ minute. According to the 
satiety scores shown in Figure 2, the highest value was observed in the OY group by the end of two hours, the lowest was observed in the Y group. Finally, the group with the highest possible food intake score was found in the OY group.

\section{Discussion}

Multiple studies have represented that foods with same amount of energy might significantly differ in terms of their capacities to increase and maintain satiety after eating. It is widely believed that plant-based fibers reduce subjective appetite and energy intake. However, different fiber types might alter these results. It is thought that subjective appetite, energy intake and control of body weight with fiber-rich diets depend on the chemical structure and physicochemical properties of the fibers rather than the total fiber intakes. Physicochemical properties, which include solubility, viscosity, water holding capacity and fermentability, not only affect the satiety capacity of dietary fibers, but also influence long-term appetite and thus the regulation of energy intake (Wanders et al. 2011).

There are various opinions concentrated on whether food flavors affect subsequent food intake. Some studies (Blundell 1991, Rogers et al. 1992) represent that individuals feel hungrier after consuming their preferred food, whereas the others (Johnson \& Vickers 1992, De Graaf et al. 1999) demonstrated that no effect on satiety exists. The increase in flavor alters instant appetite such as ending the current meal, however may not affect overall satiety. Similarly, in this study, no significant difference was found between the palatability scores of the meals. This could be interpreted as the test foods presented were found to be equally palatable and consumable, however no effect on the short-term satiety was demonstrated.

In a study by Bonnema et al., the authors compared a low protein cereal breakfast ( $10 \mathrm{~g}$ protein) to a high protein (30 g protein) and a medium protein and fiber breakfast ( $20 \mathrm{~g}$ protein $+7 \mathrm{~g}$ fiber) and evaluated their effects on appetite. The results of this study showed that, unlike the research, only a high-protein breakfast was more effective than a medium-protein breakfast with fiber. However, a medium-protein breakfast combined with fiber had a higher satiety capacity than a low-protein breakfast (Bonnema et al. 2016). Martini et al. investigated the effect of pasta formulations containing different fiber and protein on satiety and post-meal food intake. Among the formulations tested, only the fiber and protein-enriched pasta significantly reduced energy intake following ad libitum snack consumption (Martini et al. 2018). Weber et al. compared a high-protein and high-fiber diet (HPHF) to a high-fiber (HF) only and high-protein only (HP) diets, in which the HPHF diet represented the greatest reduction in energy intake for a short and medium-term, with the highest satiety effect. Also, the HF diet had more effects on satiety than the HP diet (2007). In the study, it was found that the groups in which yoghurt was consumed with oats (OY) and chickpeas (CY) had lower hunger scores, higher satiety scores and similar eating desire scores in all groups compared to the control group, which consumed plain yoghurt (Y).

Some researchers also reported that animal or vegetal proteins might exert different specific effects on the modulation of satiety feeling and energy intake. It is probably due to different digestion rates of these two protein classes. Additionally, the fiber has been shown to influence food consumption through an impact on gastric relaxation. Moreover, in long-term, fermentable fiber might regulate post-prandial satiety through the formation of propionic and acetic acid, which in turn signal secretion of gastrointestinal hormones like GLP-1 (Abou-Samra et al. 2011, Korczak et al. 2016). Adam et al., who investigated the effect of protein consumption together with fiber on satiety, concluded that soluble fermentable fiber pectin elevated satiety on high-fat diet and was more efficient than high protein consumption alone for reducing energy intake (2016). In another study conducted by Bonnema et al. with a total of 28 participants and for one day for every two weeks, beef (protein) and beans (protein + fiber) were used as test foods, and satiety scores were evaluated using a visual analog scale. Similarly, no significant difference was observed between protein and protein + fiber meals in terms of satiety scores. However, when the average values were evaluated, it was determined that the mean satiety score of bean meals was higher than that of beef meal. In addition, no variation was observed in average food intake for the rest of the day or snack consumption at subsequent meals. Generally, there was no significant difference in flavors of the two test meals, however the average flavor score of the beef meal was significantly enhanced compared to the bean meals (2015). Likewise, in our study, no significant difference was detected on energy and macronutrient composition of ad libitum lunch after test meals and during the rest of the day. However, the energy and macronutrients taken by the oat group were lower than the chickpea group, which correspondingly represent an important finding that beta glucan, the soluble fiber contained in oats, may affect short-term appetite.

When the parameters such as food intake, satiety, blood glucose level of a high-protein-high-fiber (HPHF) snack bar and a high-carbohydrate-high-fat (HCHF) snack bar were examined, Williams et al., demonstrated that the change in the glucose levels in response to HPHF bar was significantly lower compared to HCHF bar. In our study, 
a statistically significant decrease was manifested between fasting and postprandial blood glucose levels compared to the meal containing chickpea $(\mathrm{CY})$, the meal containing oats $(\mathrm{OY})$ and the control meal containing yoghurt $(\mathrm{Y})$ only. In addition, hunger, satiety, desire to eat, and appetite responses of foods consumed during the next meal had increased tendency to provide more satiety than HCHF bars. However, none of these parameters were found to be significantly different (2006).

\section{Conclusion}

As a result, this study displayed that there was no significant difference in satiety scores or subsequent food intake following three test meals that contain proteins with different fiber content. In addition, the fact that meals with oats, which contain lower fiber amount, had higher satiety scores and lower energy intake on an average basis compared to the chickpea meal. This finding suggests that the observed effect of fibers, which is considered to be quite efficient on satiety, is due to the physicochemical structure rather than the amount. Larger samples and further studies are needed to prove whether there are real differences on satiety degrees between these meals. Using a validated VAS scale is the best tool to capture this subjective fullness feeling, however multiple factors should be considered and controlled in regulating food intake.

\section{Acknowledgements}

We appreciate to Güler Ertus and Irem Oncu who were students of Istanbul Medipol University, Department of Nutrition and Dietetics for the assistance of the study.

\section{References}

Abou-Samra R, Keersmaekers L, Brienza D, Mukherjee R, Macé K. (2011). Effect of different protein sources on satiation and short-term satiety when consumed as a starter. Nutrition Journal, $10,139$. https://doi.org/10.1186/1475-2891-10-139

Adam C L, Gratz S W, Peinado D I, Thomson L M, Garden K E, Williams P A, Richardson A J, Ross A W. (2016). Effects of Dietary Fibre (Pectin) and/or Increased Protein (Casein or Pea) on Satiety, Body Weight, Adiposity and Caecal Fermentation in High Fat Diet-Induced Obese Rats. Plos One, 11(5), e0155871. https://doi.org/10.1371/journal.pone.0155871

Akhavan T, Luhovyy B L, Brown P H, Cho C E, Anderson G H. (2010). Effect of premeal consumption of whey protein and its hydrolysate on food intake and postmeal glycemia and insulin responses in young adults. The American Journal of Clinical Nutrition, 91(4), 966-975. https://doi.org/10.3945/ajen.2009.28406

Bellisle F, Drewnowski A, Anderson G H, Westerterp-Plantenga M, Martin C K. (2012). Sweetness, Satiation, and Satiety. The Journal of Nutrition, 142(6), 1149S-1154S. https://doi.org/10.3945/jn.111.149583

Blundell J. (1991). Pharmacological approaches to appetite suppression. Trends in Pharmacological Sciences, 12, 147-157. https://doi.org/10.1016/0165-6147(91)90532-W

Bonnema A L, Altschwager D K, Thomas W, Slavin J L. (2016). The effects of the combination of egg and fiber on appetite, glycemic response and food intake in normal weight adults - a randomized, controlled, crossover trial. International Journal of Food Sciences and Nutrition, 67(6), 723-731. https://doi.org/10.1080/09637486.2016.1196654

Bonnema A L, Altschwager D, Thomas W, Slavin J L. (2015). The Effects of a Beef-Based Meal Compared to a Calorie Matched Bean-Based Meal on Appetite and Food Intake. Journal of Food Science, 80(9), H2088-H2093. https://doi.org/10.1111/1750-3841.12991

De Graaf C, De Jong L S, Lambers A C. (1999). Palatability affects satiation but not satiety. Physiology and Behavior, 66(4), 681-688. https://doi.org/10.1016/S0031-9384(98)00335-7

Du H, Van Der A D L, Boshuizen H C, Forouhi N G, Wareham N J, Halkjær J, Tjønneland A, Overvad K, Jakobsen M U, Boeing H, Buijsse B, Masala G, Palli D, Sørensen T I A, Saris W H M, Feskens E J M. (2010). Dietary fiber and subsequent changes in body weight and waist circumference in European men and women. The American Journal of Clinical Nutrition, 91(2), 329-336. https://doi.org/10.3945/ajen.2009.28191

El Khoury D, Brown P, Smith G, Berengut S, Panahi S, Kubant R, Anderson GH. (2014). Increasing the protein to carbohydrate ratio in yogurts consumed as a snack reduces post-consumption glycemia independent of insulin. 
Clinical Nutrition, 33(1), 29-38. https://doi.org/10.1016/j.clnu.2013.03.010

Erhardt J. (2019). Beslenme Bilgi Sistemi (BeBiS) [Nutrition Information System] 8.1 Full Version. Stuttgart: Entwickelt an der Universität Hohenheim.

Johnson J, Vickers Z. (1992). Factors influencing sensory-specific satiety. Appetite, 19(1), 15-31. https://doi.org/10.1016/0195-6663(92)90233-V

Johnson S K, Thomas S J, Hall R S. (2005). Palatability and glucose, insulin and satiety responses of chickpea flour and extruded chickpea flour bread eaten as part of a breakfast. European Journal of Clinical Nutrition, 59, 169-176. https://doi.org/10.1038/sj.ejen.1602054

Korczak R, Timm D, Ahnen R, Thomas W, Slavin J L. (2016). High protein pasta is not more satiating than high fiber pasta at a lunch meal, nor does it decrease mid-afternoon snacking in healthy men and women. Journal of Food Science, 8(9), S2240-2245. https://doi.org/10.1111/1750-3841.13406

Martini D, Brusamolino A, Del Bo C, Laureati M, Porrini M, Riso P. (2018). Effect of fiber and protein-enriched pasta formulations on satiety-related sensations and afternoon snacking in Italian healthy female subjects. Physiology and Behavior, 185, 61-69. https://doi.org/10.1016/j.physbeh.2017.12.024

Murty C M, Pittaway J K, Ball M J. (2010). Chickpea supplementation in an Australian diet affects food choice, satiety and bowel health. Appetite, 54(2), 282-288. https://doi.org/10.1016/j.appet.2009.11.012

Panahi S, Luhovyy B L, Liu T T, Akhavan T, El Khoury D, Goff H D, Anderson G H. (2013). Energy and macronutrient content of familiar beverages interact with pre-meal intervals to determine later food intake, appetite and glycemic response in young adults. Appetite, 60, 154-161. https://doi.org/10.1016/j.appet.2012.09.018

Pittaway J K, Robertson I K, Ball M J. (2008). Chickpeas may influence fatty acid and fiber intake in an ad libitum diet, leading to small improvements in serum lipid profile and glycemic control. Journal of the American Dietetic Association, 108(6), 1009-1013. https://doi.org/10.1016/j.jada.2008.03.009

Rebello C J, O’Neil C E, Greenway F L. (2016). Dietary fiber and satiety: The effects of oats on satiety. Nutrition Review, 74(2), 131-147. https://doi.org/10.1093/nutrit/nuv063

Rogers P J, Schutz H G. (1992). Influence of palatability on subsequent hunger and food intake: a retrospective replication. Appetite, 19(2), 155-156. https://doi.org/10.1016/0195-6663(92)90018-2

Slavin J L. (2005). Dietary fiber and body weight. Nutrition, 21(3), 411-418. https://doi.org/10.1016/j.nut.2004.08.018

Slavin J. (2013). Fiber and prebiotics: Mechanisms and health benefits. Nutrients, 5(4), 1417-1435. https://doi.org/10.3390/nu5041417

Wallace T C, Murray R, Zelman K M. (2016). The Nutritional Value and Health Benefits of Chickpeas and Hummus. Nutrients, 8(12), 766. https://doi.org/10.3390/nu8120766

Wanders A J, van den Borne J J G C, de Graaf C, Hulshof T Jonathan M C, Kristensen M M, Schols H A, Feskens E J M. (2011). Effects of dietary fibre on subjective appetite, energy intake and body weight: A systematic review of randomized controlled trials. Obesity Reviews, 12(9), 724-739. https://doi.org/10.1111/j.1467789X.2011.00895.x

Weber M, Bissot T, Servet E, Sergheraert R, Biourge V, German A J. (2007). A High-Protein, High-Fiber Diet Designed for Weight Loss Improves Satiety in Dogs. Journal of Veterinary Internal Medicine, 21(6), 1203-1208. https://doi.org/10.1111/j.1939-1676.2007.tb01939.x

Williams G, Noakes M, Keogh J, Foster P, Clifton P. (2006). High protein high fibre snack bars reduce food intake and improve short term glucose and insulin profiles compared with high fat snack bars. Asia Pacific Journal of Clinical Nutrition, 15(4), 443-450. PMID: 17077058 